\title{
BANDAS DE GUERRA. JÓVENES Y NACIONALISMO EN IQUIQUE
}

BERNARDO GUERRERO JIMÉNEZ*

\begin{abstract}
RESUMEN
En el presente trabajo se analizan las bandas de guerra que congregan a estudiantes de la enseñanza media de la ciudad de Iquique. Las vemos como una actividad en que la identidad chilena, a través del proceso de chilenización, cristaliza, en la subjetividad de los jóvenes, la lealtad hacia la patria. Es además un espacio donde se construye la masculinidad de acuerdo al protocolo de la identidad nacional. Aunque haya bandas de mujeres, las de varones siguen siendo las más importantes en cuanto a prestigio y a representación simbólica del ser chileno en el Norte Grande de Chile.
\end{abstract}

PALABRAS CLAVE: JUVENTUD, BANDAS DE GUERRA, MASCULINIDAD, IDENTIDAD NACIONAL

* Sociólogo, académico Universidad Arturo Prat, Iquique, Chile.

Correo electrónico: bernardo.guerrero@unap.cl. 


\title{
FANFARRAS: JOVENS E NACIOALISMO EM IQUIQUE
}

\begin{abstract}
RESUMO
Este artigo analisa as fanfarras que congregam estudantes de ensino médio da cidade de Iquique. Vemos as fanfarras como um espaço em que a identidade chilena, através do processo de chilenização, cristaliza a lealdade para com a pátria na subjetividade dos jovens. Constitui-se também um espaço de construção da masculinidade, conforme o protocolo da identidade nacional. Embora existam fanfarras de mulheres, as fanfarras masculinas ainda são as mais prestigiadas como representação simbólica do ser chileno no norte grande do Chile.
\end{abstract}

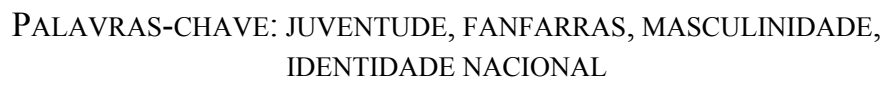

\section{MILITARY BANDS. YOUTH AND NATIONALISM IN IQUIQUE}

\begin{abstract}
War bands composed of high school students from the city of Iquique are examined. They are evidence of how Chilean identity - through a process of Chileanization - shapes up into youngsters' subjectivity loyalty towards the nation. Furthermore, it is a space where masculinity is built according to the protocol of national identity. Even though there are bands made up of women, those formed by men continue to be the most important regarding prestige and symbolic representation of Chilean citizenship in Northern Chile.
\end{abstract}

KEY WORD: YOUTH, WAR BANDS, MASCULINITY, NACIONAL IDENTITY 


\section{APRECIACIONES GENERALES}

LA JUVENTUD ES UN fenómeno que contiene muchas aristas. Se expresa esta realidad en facetas económicas, sociales, culturales y políticas. Todas ellas, en mayor o menor medida, han sido tratadas por las ciencias sociales. Con los llamados estudios culturales, las investigaciones sobre este grupo etario se han multiplicado y se han discutido diversos aspectos, como la sociabilidad, identidad, modas, corporalidades, estéticas, lenguajes, etc. Por un lado, la política pública ha visto en los jóvenes a un actor que reclama un tratamiento específico. Estos no se inscriben en los registros electorales, lo que no significa que carezcan de motivaciones, ${ }^{1}$ y, por otro, en términos generales son «productores» de malas noticias.

Una mirada a la prensa escrita o hablada nos remite a una juventud, por lo general, estigmatizada. Más allá de las variadas y múltiples estigmatizaciones, ser joven en esta época parece no ser fácil. Se le asocia a conductas hedonistas y desviadas. Consumo de drogas, delincuencia, etcétera, son parte de la narrativa con la que se construye la imagen juvenil.

En términos generales, el discurso con el que la llamada «opinión pública» se expresa respecto a este grupo etario se construye desde el mundo de los adultos. Para éstos, la juventud de hoy parece no tener futuro. Más aún si son los mismos adultos los que autocomparan su experiencia de ser joven con la de los de hoy. En ese ejercicio comparativo, la experiencia juvenil de esos adultos parece ser la «más sana», «más idealista», «con mejor música», etcétera.

Duarte plantea los siguientes estigmas que los jóvenes deben soportar: a) joven como ser inseguro de sí mismo y de los otros; b) joven como ser en transición desde la infancia hasta la adultez; c) joven como ser no productivo; d) joven como ser incompleto; e) joven como ser apático y/o sin deseo; f) joven como ser desviado; g) joven como ser peligroso; h) joven como ser victimizado; i) joven como ser rebelde y/o revolucionario; j) joven como ser del futuro, y k) joven como ideal de belleza (2006, citado por Olivares y Ulloa, 2009:245).

Para entender a los jóvenes de la década de los años 60 hay que comprender a la sociedad que la construía. Una sociedad que se articu-

1 Grupos anarquistas y del llamado voluntariado son, por dar dos ejemplos, lugares donde los jóvenes se congregan. Además de grupos articulados en torno a la música, etcétera. 
laba en torno a la idea de un modelamiento de una sociedad mejor. La utopía socialista, expresada en sus íconos como la revolución cubana y el Che, coexistía con la utopía del mundo hippie, que alzaba la consigna de «hagamos el amor, no la guerra». Las múltiples organizaciones revolucionarias que surgen durante esos años y el consumo de marihuana y el rock eran las expresiones más visibles de este fenómeno. La imagen del guerrillero y del hippie poblaba el imaginario de esos años. No había, además, una juventud única. Hablar de «juventudes» se hizo una necesidad para poder comprender mejor su desarrollo.

Los jóvenes se autorrepresentaban en afirmaciones que los hacían verse como depositarios del cambio de sociedad. Eran una especie de conciencia crítica de ésta. Su discurso era provocador. La moda era una forma, entre tantas otras, de serlo. No obstante, los jóvenes de ese entonces se inscribían en una filosofía de la historia. Esta tenía sentido, y el progreso y/o revolución era una realidad a alcanzar. En el amplio sentido de la palabra, eran militantes y revolucionarios. ${ }^{2}$

Eran jóvenes, además, que mostraban un alto índice de participación en la política. Ya sea en los partidos políticos, centros de alumnos, federaciones de estudiantes, y otras organizaciones de base. Por otro lado, se articulaban también en organizaciones deportivas, sociales y premilitares. ${ }^{3}$ Lo común a todas estas organizaciones era su grado de formalidad. Lo anterior, dicho en el sentido de que eran agrupaciones que regulaban el ingreso a ellas y su expulsión, se dotaban de reglamentos y de exigencias, de deberes y de derechos. En forma paralela, se crean grupos de amigos, de esquinas, etcétera, menos formales pero potentes en la modelación de actitudes.

En términos generales, correspondía a una sociedad que albergaba a sus miembros en instituciones sólidas. Esto en el sentido utilizado por Bauman (2002). Este sociólogo polaco nos habla de una sociedad que establece fronteras claras y delimitadas. La clase social, la patria, la etnia y el barrio aparecen como estructuras con anclajes delimitados. Hay entre ellas trasvasije, pero siempre conservando aquello que las define.

2 La canción «La juventud», del grupo musical de los años 60 Los Iracundos, así lo refleja: «Corazones agitados/extendamos nuestras manos/que el mañana se aproxima más y más/natural es que luchemos/por un mundo mejor/con la fuerza que nos da/ la juventud, la juventud, la juventud...».

3 Las brigadas premilitares fueron creadas bajo el gobierno de Gabriel González Videla (1946-1952) en 1948. 
Los jóvenes que nos interesa analizar en este artículo se generan y desarrollan en el marco de una modernidad sólida. Bauman cuando desarrolla esta idea refiere que este tipo de modernidad actúa anclando a los sujetos a referencias claras y estables. Y, por lo mismo, dota a los actores sociales de certezas. El cambio, si bien es un elemento «natural» de la modernidad, en esta etapa se halla controlado. No sucede lo mismo en la llamada modernidad líquida. En ésta, las referencias al espacio y al tiempo desaparecen (Bauman, 2002).

En la modernidad sólida, las referencias como la clase social, la nación, la etnia y el barrio, entre otras, operan a la manera de «cables a tierra» de los sujetos. Son, además, según lo plantean Berger y Neuhaus (1997), «estructuras intermedias» que otorgan sentido a sus participantes. La primera modernidad reemplazó al viejo orden que ataba al sujeto a la tierra, a lo local. De allí la célebre expresión de Marx de «que todo lo sólido se desvanece en el aire» (1988). La identidad nacional la hemos agrupado, según una investigación llevada a cabo el año 2009, en lo que hemos denominado identidades largas. Largas en el sentido de que se vienen produciendo desde la anexión del Norte Grande a la soberanía nacional. En el caso del nacionalismo, ha sido la escuela nacional, el servicio militar obligatorio, entre otros, los mejores instrumentos que se ha tenido desde Santiago para socializar el sentimiento patrio. La idea de la comunidad imaginada de Anderson encuentra en el aula su mejor expresión (1993). La construcción de un ciudadano civilizado - no indio, por lo mismo, no peruano o boliviano- ocupa un lugar central en el currículo. Con la identidad nacional convive la de clase, la salitrera, la deportiva, las religiosas populares y las andinas. El juego entre todas ellas tiende a producir resultados tanto en la construcción de identidad nacional y/o regional, o ambas (Guerrero, 2009).

En el marco de este trabajo queremos reflexionar sobre un espacio y un tiempo de participación juvenil que es posible observar en casi todo Chile. Aquí nos basamos en observaciones y entrevistas a miembros de bandas de guerra de la ciudad de Iquique. Estos bien pueden ser tildados de sólidos en el sentido anteriormente señalado. Se trata de grupos de jóvenes, estudiantes de enseñanza media, hombres y mujeres, que todos los 21 de mayo rinden homenaje a Arturo Prat.

Estas bandas de guerra las podemos ver como espacio de confluencia y de articulación entre la escuela y el servicio militar obligatorio. Un territorio donde concurren los instrumentos preferidos del Estado Nación para crear identidad nacional. Esto lo podemos ver 
como una hipótesis de trabajo. No se trata sólo de internalizar valores y creencias, sino también de modelar cuerpos. Esto en el sentido de normalizar según el canon dominante, lo que se entiende por caminar y sentarse como hombres. Así, el cuerpo militar, erguido, de pelo corto, afeitado, sintetiza lo que el poder requiere de estos jóvenes. El desfilar pone en movimiento un conjunto de atributos ya ensayados desde la educación preescolar. A medida que el niño va creciendo, la marcialidad se va acentuando. Un dato interesante. Tradicionalmente, estos grupos estaban integrados exclusivamente por varones. Desde hace ya unos años existen bandas de guerra compuestas por mujeres, que también cumplen funciones de dar abrigo, calidez; es decir, brindar lo que en otros grupos también es posible hallar.

Este artículo trata sobre la sociabilidad e identidad de un grupo de jóvenes de Iquique. En otras palabras, se reflexiona acerca de un tipo especial de jóvenes que construyen su identidad y sociabilidad según referentes clásicos como la nación, la religión y el deporte. Nomino a este tipo de juventud «jóvenes del día». En oposición a los llamados «jóvenes de la noche», asociados, por lo general, a una forma específica de ocupar la ciudad a través de desplazamientos determinados por un tipo de nomadismo, y que con frecuencia son etiquetados bajo la categoría de tribus urbanas, según la célebre metáfora de Maffesoli (1997). Trata de las sociabilidades posibles de advertir en las bandas militares, que tienen sus antecedentes más remotos en las llamadas brigadas juveniles premilitares.

En un trabajo anterior, Guerrero (2003) planteó la idea de que la identidad cultural del Norte Grande de Chile se levanta sobre tres ejes: la religión popular, el deporte, y el nacionalismo. Estos tres ejes, además - factor importante a subrayar-, tienen como común denominador el cuerpo. En otras palabras, se trata de una identidad que se despliega corporalmente. Desfilar, jugar y bailar constituyen los pivotes sobre los que la identidad cultural del Norte Grande se estructura. El 21 de mayo, el 16 de julio y cada domingo en las canchas se ponen en escena tales identidades.

\section{APRECIACIONES METODOLÓGICAS}

En términos metodológicos, el presente trabajo lo construimos sobre la base de la observación, entrevistas y análisis de textos aparecidos en la web. La primera, por cuanto hemos asistido desde hace ya varios años a ensayos de estas bandas de guerra. Y luego hemos ido a verlos 
desfilar para el 21 de mayo y para el aniversario de sus establecimientos educacionales. Por otro lado, realizamos entrevistas a miembros de bandas de liceos y a participantes de las antiguas brigadas premilitares. Y en la web nos hemos encontrado con material fotográfico, videos y discusiones, a favor y en contra de estas prácticas. En las entrevistas hemos notado, de parte de quienes participaron en los años 60 y 80, un gran orgullo por pertenecer y ser miembros de esas organizaciones. Algunos, por ejemplo, de las brigadas premilitares, una vez realizada la conscripción, se contrataron y han jubilado como miembros de las Fuerzas Armadas.

\section{JÓVENES QUE DESFILAN}

A partir del mes de marzo, la ciudad de Iquique se llena de aires marciales. No se trata tan sólo de que los militares, aviadores y marinos ensayen sus rutinas para celebrar un aniversario más del Combate Naval de Iquique, ocurrido el 21 de mayo de 1879, sino también de que bandas de jóvenes de la enseñanza media cada tarde ensayan su desfile. Son las bandas de guerra que han crecido al alero de los establecimientos educacionales de la ciudad. ${ }^{4}$

En el caso de las bandas de guerra, las integran jóvenes que pertenecen a esta modernidad sólida. Las referencias están en el nacionalismo que remite a comportamientos patrióticos. Hay que advertir, eso sí, que éstos también participan de las redes sociales e internet. De alguna manera, son sólidos y líquidos, dependiendo de la situación.

Son «jóvenes sólidos» que se inscriben en una tradición cultural maciza y potente del norte grande de Chile. Son hijos y continuadores del proceso de chilenización, ocurrido como consecuencia de la Guerra del Pacífico. Son además «jóvenes del día» en el sentido de que desarrollan sus prácticas mayormente en horario diurno. Cuando decimos esto, hay que entenderlo como ese espacio en que «las cosas

4 En la década de los 60 sólo cuatro liceos de humanidades o de enseñanza media atendían a los estudiantes. En los 90, con el fenómeno de los establecimientos particulares y particulares subvencionados, aumenta la oferta educacional. Este proceso también se da en la pampa salitrera. Tengo una foto de la Brigada General Bulnes $\mathrm{N}^{\circ} 10$ de la Oficina Humberstone del año 1949. Si bien es cierto pertenece a los Boys Scouts, bien podría verse como un antecedente, ya que la mayoría de sus integrantes son jóvenes. 
son como son». O bien, como la razón dice que son. Las coordenadas de lo permitido y de lo no permitido aparecen rigurosamente precisadas. En este sentido, Maffesoli (1998) nos habla de un saber diurno y de un saber nocturno. El primero alude a cuestiones ligadas al poder, a una definición cartesiana y oficial de la realidad, etcétera. Por el contrario, los jóvenes de la noche tienen que ver con el caos, el desorden, el desborde, entre otras cosas.

Estos son jóvenes que calzan con algunas características básicas que se le atribuyen a la juventud. Tienen entre 14 y 18 años, son estudiantes y, por lo tanto, no disponen aún de autonomía en términos económicos. Son solteros. Gran parte de su sociabilidad e identidad la construyen bajo el alero de la escuela y de pertenecer a estructuras como las bandas de guerra. Ubicada en el rango de las actividades extraacadémicas, desarrollan su labor al finalizar su horario regular. Ensayan sus actividades en lugares cercanos a sus establecimientos educacionales, y en horarios vespertinos ejecutan sus rutinas. Pero, además, sus integrantes se enmarcan en el ideal normativo de la sociedad adulta: son buenos muchachos. Un ideal que se construye en torno a la idea de la disciplina, del vestirse ordenadamente, sin tatuajes, etcétera.

\section{NACIONALISMO Y ESCUELA}

La anexión de Tarapacá a la soberanía nacional implicó la movilización de recursos tanto materiales como simbólicos para conseguir que las nuevas fronteras geográficas coincidieran con las culturales. Estas últimas, definidas según el canon establecido desde la capital. Este proceso ha sido bien documentado por Podestá (2003). Los contenidos del nacionalismo fueron en gran medida, pero no exclusivamente, movilizados por la escuela nacional. Las prácticas de los deportes también ayudó a anclar en la subjetividad de los tarapaqueños las ideas y creencias dominantes del credo nacionalista (Guerrero, 2008). Pero a diferencia de la escuela, estas instituciones ayudaron, además, a crear una identidad regional.

La escuela se convirtió en el lugar central para reproducir la gesta del 21 de mayo de 1879. Este combate naval entre fuerzas chilenas y peruanas fue el hito épico que funcionó como un potente dispositivo moral para el triunfo chileno sobre Perú y Bolivia. La figura de Prat se alzó con una fuerza que lo ha convertido en el héroe nacional sin discusión (Sater, 2005). Un ícono que ha alcanzado ribetes mitológicos. 
La lectura de poemas, el recitado de su arenga, dibujos que narran el hundimiento de la Esmeralda, Prat saltando a la cubierta del Huáscar constituyen los tópicos recurrentes. Los más pequeños son disfrazados de marineros, etcétera.

Mayo fue declarado mes del mar en honor a lo precisado. Las tiendas se ornamentan con los motivos ya identificados. El 20 de mayo, todos los establecimientos educacionales, desde parvularios hasta los de educación superior, desfilan en homenaje al héroe. Este proceso ha ido, sin embargo, en aumento. En los años 50 aproximadamente, e incluso antes, algunos liceos como el Colegio Salesiano «Don Bosco» ${ }^{5}$ formaron una banda de guerra para acompañar a su plantel en el desfile. Luego, el Liceo de Hombres hizo lo mismo. En la actualidad, casi todos los colegios cuentan con banda de guerra, e incluso algunas la integran mujeres.

Este proceso se ha visto ayudado por la Zona Franca de Iquique, pues por las franquicias que posee provoca una baja considerable en los costos de los instrumentos musicales. Con ello se han visto favorecidas todas las expresiones musicales de la ciudad: grupos de rock, bandas de bronces que acuden a la fiesta de La Tirana y, por cierto, las bandas de guerra.

En la década de los años 50, por mediación de las Fuerzas Armadas se crean las brigadas premilitares. Cada rama de los institutos castrenses formó una. La armada creó la «Carlos Condell»; la aviación, «Los Cóndores», y carabineros la «Hernán Trizano». ${ }^{6}$ Estas tres instituciones estaban formadas por jóvenes, y eran dirigidas por un suboficial de la respectiva rama.

Estas estructuras operaban como mecanismos de chilenización que complementaban lo que hacía la escuela. La rutina era juntarse tres veces a la semana y desfilar las veces que el calendario ritual nacionalista lo aconsejaba. Para el 21 de mayo, desfilaban el día 17 en

5 Contó este colegio con una banda instrumental que luego devino en banda de guerra.

6 Hay quienes discrepan de la visión tradicional (defendida por Carabineros, principalmente) que exalta a Trizano como un héroe, y buscan desempolvar algunas características negativas de su personalidad. Los mapuches, a modo de ejemplo, lo consideran un bandido y un hombre despótico y autoritario, que no conoció límites a su proceder.

Sin embargo, en aquel tiempo fue muy apreciado por los propietarios agrícolas chilenos y por los colonos suizos, italianos y alemanes que por aquella época se establecieron en La Araucanía. 
forma exclusiva. Sus integrantes usaban uniformes militares iguales a los que utilizaban las ramas de las fuerzas armadas. Esta forma de aprovechar el tiempo libre era complementaria al deporte y, en muchos de los casos, competía con las ofertas de otros grupos, por ejemplo los boy scouts, por nombrar uno.

Además, correspondían a instituciones que funcionaban bajo la lógica de un regimiento. La disciplina y los rasgos asociados a ella - corte de pelo, marcialidad, gallardía e incluso un sentido de la virilidad - eran producidos en esos ambientes. Hacer el servicio militar se asociaba a una ocasión «para hacerse hombres».

Lo anterior, en una lógica que vinculaba el nacionalismo con la masculinidad. En otras palabras, ser masculinos se inscribía en el horizonte de ser chileno. Valores cultivados como consecuencia de la Guerra del Pacífico. Y el militar, de una u otra manera, sintetizaba valores como la valentía, la gallardía, la virilidad, la hombría. La figura del roto chileno, del obrero pampino, del boxeador, simbolizaba la idea de una masculinidad dura, que el soldado habría de monopolizar en forma hegemónica. La estampa del soldado dominaba.

Con la desaparición de las brigadas premilitares, ese espacio, de una $\mathrm{u}$ otra manera, lo ocupan las bandas de guerra de los establecimientos educacionales, pero con la diferencia de que se multiplican. Cada liceo, en lo posible, debe contar con su propia banda. La competencia que se produce y el prestigio que otorga pertenecer a éstas es un factor importante a la hora de explicar el porqué de su proliferación.

\section{MASCULINIDAD DURA Y JÓVENES}

Ser hombre, comportarse como tal, y todo el protocolo que acompaña a este tipo de conducta, encuentra en la banda de guerra su mejor expresión. La hombría se modela a través de estas prácticas. Desfilar se constituye en un tópico que produce virilidad.

Muchos de sus integrantes perciben su pertenencia a estos grupos como expresión de hombría. Este relato que hemos extraído de internet es decidor:

Bandas de guerra, costumbre iquiqueña, costumbre machota.

Si existe una costumbre machota, arraigada profundamente en nuestro terruño, son las bandas de guerra, un espacio donde sólo tocan los verdaderos hombres y es que hay que ser masoca para que guste como se 
organiza esto, con jefes que te tratan a patadas y a voces de mando, con maratónicas jornadas de ensayo, marchas forzadas y largas horas parados al sol, sólo para exhibir con orgullo marcial los sones de tu banda en la comunidad.

Y es más específico:

Toqué por varios años en la gloriosa banda del Liceo de Hombres de Iquique, la mejor de la ciudad; practicábamos los encajonamientos por horas, hacíamos «paseos» de instrucción a la playa donde nos aporreaban y castigaban si cometíamos un error; ensayábamos semanas para ser dignos y orgullosos miembros de la banda. Pero todo ese trabajo rendía sus frutos cuando marchabas el 21 de mayo con el uniforme impecable, sonando de manera perfecta ante el monumento a Prat y recibías el aplauso y admiración de toda una ciudad.

Reiterando las ideas anteriores:

Estar en una banda de guerra era una actividad netamente de machos y había que ser bien macho pa aguantar tanta huevá, te tenía que gustar el estilo marcial militar, aprendías lo que era el compañerismo, el orgullo por los símbolos y la disciplina, te superabas a ti mismo y avanzabas respetando los méritos ajenos y la antigüedad.

Para luego desacreditar a otro tipo de jóvenes:

Muchos de estos valores que son típicamente masculinos se están perdiendo en la actualidad con tanto niño pokemon formado por MTV y animés andrógenos, por lo que reivindicar las pocas costumbres de machos que aún quedan es fundamental; así es que amigos, para el próximo desfile que vean presten atención a las bandas y bríndenles su apoyo, ya que estarán apoyando a verdaderos machotes que continúan y mantendrán las tradiciones de hombres iquiqueños.

(http://elclubdelosmachotes.blogspot.com/2007/07/bandas-de-guerracostumbre-iquiquea.html).

Este relato sintetiza muy bien las ideas que hemos expuesto. Lo curioso del caso, y que llama la atención, lo constituye la idea que las bandas de guerra sean una costumbre iquiqueña. No lo podemos afirmar con certeza, pero es plausible que así sea, ya que el vigoroso proceso de chilenización que afectó al Norte Grande pudo haber producido un fenómeno como éste. 
Otro joven, de otra sensibilidad seguramente, responde a lo anterior con el siguiente comentario:

Oye weón, de bandas chantas está lleno todo Chile, sobre todo Santiago y en todas las bandas participan minas hasta en las de los milicos, así que más que machotas son para weones acomplejados que se creen milicos.

Otro elemento ya advertido de estos grupos se vincula con las nociones de orden y de disciplina. Así se expresa en este otro texto de internet:

Los felicito por su agrupación, ya que las bandas de guerra escolares dan una visión de disciplina y orden a los jóvenes, los cuales se unen por el compañerismo y amor a la música. Sigan así, ya que ya son muchas las agrupaciones que están creando sus bandas de guerra escolares. Un gran saludo del webmaster del sitio de la banda de guerra Juan Ignacio Molina de Linares. Séptima Región.

(www.elmorrocotudo.cl/admin/render/noticia/4788).

Algunos de los criterios que utilizan en los liceos para admitir o no a los estudiantes tienen que ver con su rendimiento. $\mathrm{Y}$, obviamente, poseer cierta destreza musical.

Pertenecer a una banda, además de que les permite contar con un espacio para solventar el tiempo libre, y para el desarrollo de una identidad, les proporciona a los jóvenes distinción respecto de sus pares. Pero esta distinción funciona en forma diferenciada, en una suerte de réplica a lo que toda agrupación de ese tipo posee. De este modo, el tambor mayor o guaripola ${ }^{7}$ concentra todo el prestigio. El resto se va distribuyendo según la posición en la banda y el tipo de instrumentos que ejecutan. Los que tocan la caja, y por ir en la primera fila, resultan más prestigiados que los que tocan los pitos. «Esos son unos pajeros» me dice un profesional que tocó la caja en primera fila (entrevista, 14 abril de 2009). Este mismo entrevistado me dice que en los años 80 , ser miembro de esa organización le permitía conocer a mujeres de los liceos femeninos.

Pero las bandas también implican obligaciones. Esto se relaciona con que sus integrantes deben ser mejores estudiantes; sacarse buenas

7 Bastón de mando que se usa para dirigir un desfile. Se le conoce también como tambor mayor. 
notas, andar bien vestidos. A cambio de ello, pueden gozar de algunas licencias: salir antes de clases por los ensayos u otras obligaciones, etcétera. El honor de pertenecer a una banda de este tipo se transfiere, además, a que representan al colegio. Y esta condición se hace sentir. A menudo, para los alumnos el prestigio de un establecimiento educacional se mide por la calidad de su banda, cuyos miembros pueden oscilar, según la ocasión, entre 30 a 50 personas.

Las bandas de guerra deben combinar adecuadamente el paso con el ritmo mientras tocan sus instrumentos. La banda, según un integrante de la del Don Bosco, «es un equipo que debe funcionar en sincronía» (entrevista, 10 de mayo 2009). Todo el aprendizaje se basa en la repetición casi mecánica de las marchas. El himno a Yungay, la marcha Radetzky, entre otros, gozan de mayor prestigio. Sin dejar de lado la versión marcial del «Submarino Amarillo» de Los Beatles.

\section{PROHIBIR LAS BANDAS}

De acuerdo a lo anterior, se puede explicar el rechazo que causó en la opinión pública de Iquique el ordinario $\mathrm{N}^{\circ} 01 / 1187$, en el cual, desde la Secretaría Regional Ministerial de Educación, con fecha 23 de mayo del 2000, y por petición del intendente de la época, se dice: «Considerando que la formación que entregan las escuelas y los liceos es de carácter eminentemente cívico y de formación para la vida ciudadana, valores reflejados en los Objetivos Fundamentales Transversales que deben manifestarse en toda actuación de los alumnos y, por expresas instrucciones del Sr. Intendente Regional Don Jorge Tapia Valdés, se solicita que las bandas escolares se abstengan de cantar himnos militares, hacer paso de parada o cualquier otra manifestación de corte militar». Este instructivo desencadenó una serie de reacciones adversas. Y de todos los sectores políticos de la ciudad. Incluso tuvo cobertura nacional a través de El Mercurio (3 de junio de 2000). Y no era para menos. Se trataba de evitar una expresión de la identidad nacional en territorios ocupados por el Estado nacional. Y, además, ejecutada por jóvenes correctos. Esta medida fue rápidamente dejada a un lado.

\section{CONCLUSIONES PROVISORIAS}

Lo dicho anteriormente adquiere sentido en la medida en que aceptemos que la realidad de la globalización en ciudades como Iquique, portadora de una gran identidad nacionalista, no necesariamente merma el arraigo 
nacional. Es más, seguimos aquí la hipótesis de Podestá (2006) que afirma que en territorios que comparten fronteras, como es el caso de Tarapacá, la presencia del Estado nacional sigue siendo fuerte.

Si bien es cierto ya no existen las brigadas premilitares como las nombradas con anterioridad, su lugar ha sido ocupado ahora por las llamadas bandas de guerra. Pero éstas son más laxas, menos militares, ya que sólo alcanzan su momento culminante para el 21 de mayo y cuando sus establecimientos educacionales están de aniversario. Pero de igual forma activan, reproducen y socializan con los valores que la chilenización afirma como positivos.

A diferencia de los años 60, cuando estas bandas o brigadas premilitares interactuaban con los jóvenes revolucionarios, rockeros o deportistas, en la actualidad conviven con grupos juveniles que portan otras sensibilidades y otros discursos estéticos. Hay que anotar, eso sí, que estos mismos jóvenes son los que también integran grupos de música andina en los que ejecutan instrumentos de bronce, pero interpretando ahora ritmos andinos. Además, suelen participar en la barra de Municipal Iquique.

La noción de masculinidad dura de la década de los 60 que se expresa en los actuales años se verifica asimismo en la que aportan las tribus urbanas, muy diferentes en su estructuración. Podemos decir que en la misma ciudad conviven jóvenes sólidos con jóvenes líquidos.

Las fronteras y los discursos de la juventud que se reproducen en torno a las bandas premilitares sigue la larga tradición que el proceso de chilenización instauró una vez concluida la Guerra del Pacífico. La liturgia y el ritual nacionalistas encuentran en estos jóvenes un nuevo canal de reproducción.

El territorio de las bandas de guerra, en tanto confluencia de la escuela y el servicio militar obligatorio, opera como una buena fuente de expresión y de reafirmación de la identidad nacional. Y más aún en una zona como el norte grande, que posee en la actualidad dos características. Ser ciudades fronteras y vivir la globalización en forma simultánea. Jóvenes del día y de la noche, jóvenes sólidos y líquidos, habitan un mismo lugar, pero percibidos de formas diferentes.

IQUIQUE (CHILE), MARZO 2010

RECIBIDO: ABRIL 2010

ACEPTADO: MAYO 2010 


\section{REFERENCIAS BIBLIOGRÁFICAS}

ANDERSON, BENEDICT (1993): Comunidades imaginadas. Reflexiones sobre el origen y la difusión del nacionalismo. México: FCE.

BAUMAN, ZYGMUNT y KEITH TESTER (2002): La ambivalencia de la modernidad y otras conversaciones. Barcelona: Paidós.

BERger, PETER y Richard NeuHAus (1993): «Potenciar al ciudadano. El rol de las estructuras intermedias en las políticas públicas». Estudios Públicos No49. Santiago: CEP.

BERMAN, MARShall (1988) Todo lo sólido se desvanece en el aire. La experiencia de la modernidad. Buenos Aires: Siglo XXI.

GHIARDO, FELIPE y OSCAR DÁVILA (2008) Trayectorias sociales juveniles. Ambivalencias y discursos sobre el trabajo. Valparaíso: INJUV y Ediciones CIDPA.

GUERRERO, BERNARDO (2009a): Estudio para el fortalecimiento de la identidad cultural en Tarapacá. Iquique: Subdere, Gobierno Regional de Tarapacá, Instituto Isluga y Universidad Arturo Prat. (2009b): «Cuerpos populares y masculinos. Sociología del cuerpo regional». Ponencia presentada al seminario Cuerpo y Sociedad. Universidad Arturo Prat, Iquique.

(2008): «Fútbol y nacionalismo en el norte grande de Chile». En RODRIGO HERRERA y JOSÉ VARAS (compiladores): Fútbol, cultura y sociedad. Santiago: Universidad Academia de Humanismo Cristiano.

— (2004): «Bailar, jugar y desfilar: la identidad cultural de los nortinos». Revista de Ciencias Sociales $\mathrm{N}^{\mathrm{o}} 14$. Iquique: Departamento de Ciencias Sociales, Universidad Arturo Prat.

MAFFESOLI, MiCHEL (1997): Una visión intuitiva del mundo contemporáneo. Barcelona: Paidós.

MELÉNDEZ, GINA (2007): «Desfiles militares como mecanismos de construcción de identidad masculina y regional». Tesis para optar al grado de licenciada en sociología, Universidad Arturo Prat, Iquique.

Olivares, Catalina y Mónica UlloA (2009): «Dimensiones de análisis de las culturas juveniles en un liceo prioritario de la provincia de San Antonio». Revista Observatorio de Juventud N²4. Santiago: INJUV.

PODESTÁ, JUAN (2006): «Globalización, mercado, estado y modernismo, los debates pendientes en América Latina». Revista de Ciencias Sociales $\mathrm{N}^{\mathrm{o}} 17$. Iquique: Departamento de Ciencias Sociales, Universidad Arturo Prat. 
(2003): La invención de Tarapacá. Iquique: Ediciones Campvs, Universidad Arturo Prat.

SATER, William F. (2005): La imagen heroica en Chile. Arturo Prat, santo secular. Santiago: Centro de Estudios Bicentenario. 